\title{
Air pollution, inflammation and preterm birth in Mexico City: Study design and methods
}

\author{
Marie S. O'Neill, Ph.D. a , Alvaro Osornio-Vargas, M.D., Ph.D. ${ }^{b}$, Miatta A. Buxton, M.P.H. ${ }^{a}$, \\ Brisa N. Sanchez, Ph.D. ${ }^{a}$, Leonora Rojas-Bracho, Sc.D. ${ }^{c}$, Marisol Castillo-Castrejon, M.Sc. ${ }^{e}$, \\ Irina B. Mordhukovich, M.S.P.H. ${ }^{d}$, Daniel G. Brown, Ph.D. ${ }^{f}$, and Felipe Vadillo-Ortega, M.D.e \\ aUniversity of Michigan School of Public Health, Ann Arbor, MI, USA \\ bInstituto Nacional de Cancerología, Mexico City, Mexico (where work was done) \\ CInstituto Nacional de Ecología, Mexico City, Mexico \\ dUniversity of North Carolina Gillings School of Public Health, Chapel Hill, NC, USA \\ eUniversidad Nacional Autonoma de Mexico, Unidad Mixta Facultad de Medicina, UNAM/ \\ INMEGEN, Instituto Nacional de Medicina Genómica. Facultad de Medicina, Av. Universidad \\ 3000, Delegacion Coyoacan, Mexico, D.F 04510, Mexico \\ fUniversity of Michigan, School of Natural Resources \& Environment, Ann Arbor, MI, USA
}

\section{Abstract}

Preterm birth is one of the leading causes of perinatal mortality and is associated with long-term adverse health consequences for surviving infants. Preterm birth rates are rising worldwide, and no effective means for prevention currently exists. Air pollution exposure may be a significant cause of prematurity, but many published studies lack the individual, clinical data needed to elucidate possible biological mechanisms mediating these epidemiological associations. This paper presents the design of a prospective study now underway to evaluate those mechanisms in a cohort of pregnant women residing in Mexico City. We address how air quality may act together with other factors to induce systemic inflammation and influence the duration of pregnancy. Data collection includes: biomarkers relevant to inflammation in cervico-vaginal exudate and peripheral blood, along with full clinical information, pro-inflammatory cytokine gene polymorphisms and air pollution data to evaluate spatial and temporal variability in air pollution exposure. Samples are collected on a monthly basis and participants are followed for the duration of pregnancy. The data will be used to evaluate whether ambient air pollution is associated with preterm birth, controlling for other risk factors. We will evaluate which time windows during pregnancy are most influential in the air pollution and preterm birth association. In addition, the epidemiological study will be complemented with a parallel toxicology invitro study, in which monocytic cells will be exposed to air particle samples to evaluate the expression of biomarkers of inflammation.

\footnotetext{
(C) 2012 Elsevier B.V. All rights reserved.

Address correspondence to Marie S. O'Neill, University of Michigan School of Public Health, 6631 SPH Tower, 109 South Observatory, Ann Arbor, Michigan 48109-2029 Phone: (734) 615-5135, Fax: (734) 936-7283, marieo@ umich.edu.

Publisher's Disclaimer: This is a PDF file of an unedited manuscript that has been accepted for publication. As a service to our customers we are providing this early version of the manuscript. The manuscript will undergo copyediting, typesetting, and review of the resulting proof before it is published in its final citable form. Please note that during the production process errors may be discovered which could affect the content, and all legal disclaimers that apply to the journal pertain.
} 


\section{Keywords}

air pollution; epidemiology; toxicology; preterm birth; inflammation; Mexico City

\section{Introduction}

Preterm births, defined as delivery before 37 weeks of gestation, represented $12.5 \%$ of live births in the U.S. in the year 2004 (Behrmanand Butler, 2007). Preterm birth is a leading cause of perinatal mortality, representing $75 \%$ percent of infant deaths and $62 \%$ of early neonatal deaths among pregnancies in six developing countries (Ngoc et al., 2006). Additionally, the rate of preterm deliveries is steadily rising in the U.S. and worldwide (Behrmanand Butler, 2007). The United Nations Millennium Development Goals include reducing child mortality by two thirds between the years 1990 and 2015 (United Nations2000). Reducing the incidence of preterm birth may contribute toward meeting this goal. Prematurity has major repercussions on infant morbidity that range from long-term neurologic disability (especially cerebral palsy) to pulmonary outcomes with no current effective means of prevention. The Institute of Medicine (IOM) 'Committee on Understanding Premature Birth and Assuring Healthy Outcomes', which issued a report in early 2007 regarding current knowledge on the causes and consequences of preterm birth, characterized preterm birth as a complex disease with multiple influences, including "individual-level behavioral and psychosocial factors, neighborhood social characteristics, environmental exposures, medical conditions, infertility treatments, biological factors, and genetics, all of which vary by population (Behrmanand Butler, 2007). The IOM placed among its priority recommendations the need to 'conduct etiologic and epidemiologic investigations' about preterm birth.

\subsection{Air pollution and preterm birth}

Several epidemiologic studies have evaluated air pollution and preterm delivery (Leem et al., 2006; Lin et al., 2001; Liu et al., 2003; Ritz et al., 2007). However, most studies have relied on population birth registries, except for one case-control study nested within a birth registry cohort (Ritz et al., 2007). One study used proximity to an industrial source as an exposure proxy (Lin et al., 2001) and estimated exposure using data from ambient air pollution monitoring networks which routinely measure gaseous and particulate pollutants regulated by health-based standards in many countries (WHO, 2006). These pollutants include: total suspended particles (TSP); particulate matter less than 10 and 2.5 microns in aerodynamic diameter $\left(\mathrm{PM}_{10}\right.$ and $\mathrm{PM}_{2.5}$, respectively); carbon monoxide $(\mathrm{CO})$, ozone $\left(\mathrm{O}_{3}\right)$, sulfur dioxide $\left(\mathrm{SO}_{2}\right)$, and nitrogen dioxide $\left(\mathrm{NO}_{2}\right)$. Previous reviews of air pollution and preterm birth epidemiology literature found that evidence was insufficient and inadequate to infer causality or make a strong conclusion about the association of air pollution with preterm delivery, in part because of inconsistencies in study design and potentially selective reporting of results for particular measured pollutants (Glinianaia et al., 2004; Maisonet et al., 2004; Sram et al., 2005). Studies published since those 2004 and 2005 reviews have found positive associations with preterm delivery. In addition, Chapter 8 'The Role of Environmental Toxicants' in the 2007 IOM report which reviewed 21 published studies concluded that "the epidemiological findings suggest that air pollution contributes to a woman's risk for preterm birth" (p. 236), most notably for particulate matter and $\mathrm{SO}_{2}$ (Behrmanand Butler, 2007). Evidence for a role of $\mathrm{CO}, \mathrm{NO}_{2}$, and $\mathrm{O}_{3}$ inconclusive, but a recently published Los Angeles study adds new evidence strengthening the case for a role of $\mathrm{CO}$ in the etiology of prematurity (Ritz et al., 2007), and other recent work suggests that $\mathrm{O}_{3}$ may be relevant (Hansen et al., 2006; Salam et al., 2005). 


\subsection{Research gaps}

The limited and inconsistent knowledge on the epidemiology of air pollution and prematurity, among other perinatal health issues, inspired two international workshops, held in 2007, to discuss ways to advance the science (Slama et al., 2008; Woodruff et al., 2009). Research needs described by the previously published reviews and discussed by the experts convened for these 2007 workshops include: evaluating exposure at various time windows during pregnancy (gestational months or trimesters); examining cumulative effects; including the range of routinely monitored pollutants, instead of selected subsets, and reporting results with and without adjustment for other air pollutants; assessing spatial as well as temporal variability in pollution exposure; using individual measurements of exposure to ambient air pollution; estimating gestational age using fetal ultrasound; examining source and chemical composition of particles; better understanding differences in underlying susceptibility and access to care of various populations studied; obtaining information on mechanisms underlying epidemiological associations; and using biomarkers of both exposure and biological response to air pollution. To accomplish this diverse range of research goals, interdisciplinary collaborations between "environmental and perinatal epidemiologists, molecular biologists and environmental toxicologists" have been encouraged (Glinianaia et al., 2004). This paper describes a study designed with interdisciplinary collaboration, which aims to understand mechanisms by which air pollutants may influence preterm delivery risk. First, we discuss the knowledge motivating this study.

\subsection{Potential mechanisms for air pollution and preterm delivery}

Several biological mechanisms, some of which may be specific to particular time windows in gestation (Liu et al., 2003), are hypothesized to mediate the association between air pollution and preterm delivery, but the specific biologic pathways remain largely unknown. Although the gaseous pollutants are distinct compounds, particulate matter is a complex mixture of suspended aggregates of transition metal oxides, ammonium nitrate and sulfate salts, organic material such as polycyclic aromatic hydrocarbons, and protein complexes (Monn and Becker, 1999). Concentration, size, and composition affect particle toxicity. Coarse fraction particles, between 2.5 and $10 \mu \mathrm{m}$ in diameter $\left(\mathrm{PM}_{2.5-10}\right)$, are emitted primarily by natural sources and include geogenic material, resuspended dust, pollen, and bacteria (Monn and Becker, 1999). These larger particles, upon inhalation, are either removed or are deposited on the ciliated epithelium in the tracheobronchial region ( $\mathrm{Nel}$ et al., 2001). Fine fraction particles $\left(\mathrm{PM}_{2.5}\right)$ are mostly associated with anthropogenic, combustion-related emission sources, such as vehicles. These smaller particles have a higher chance of depositing into the alveolar region of the lungs and potentially entering the circulatory system (Monn and Becker, 1999; Sioutas et al., 2005).

\subsection{Studying air pollution and the inflammatory pathway to preterm birth}

Particulate and gaseous pollutants routinely monitored in many parts of the world $\left(\mathrm{PM}_{2.5}\right.$, $\mathrm{PM}_{10}, \mathrm{O}_{3}, \mathrm{SO}_{2}, \mathrm{NO}_{2}, \mathrm{CO}$ ) present some epidemiologic evidence as contributors to the etiology of preterm delivery. Mechanistic evidence suggests that they may contribute to the inflammatory processes of relevance to preterm delivery, for which pro-and antiinflammatory cytokines are key markers. We next describe the design of our ongoing study examining air pollution effects on inflammatory processes related to preterm birth.

\section{Material and Methods}

Our study seeks to understand the relation between ambient air pollution exposure and preterm delivery, including effect modifiers, in a cohort of pregnant women who are clinically monitored on a monthly basis, using both epidemiological and toxicological 
approaches to shed light on mechanistic pathways that may underlie the associations. The study setting is metropolitan Mexico City where pollutant levels are high and a large population is exposed. We examine both preterm birth outcomes and the association between air pollution and markers of inflammation that are emerging as potential screening tools for providing early indication of preterm delivery risk. Our hypothesis is that air pollution exposure contributes to the etiology of preterm birth and that it influences the mechanistic pathway of inflammation.

\subsection{Study population}

We are enrolling a cohort of 800 pregnant women living in Mexico City. These women, who reside in diverse regions of metropolitan Mexico City, are seen monthly over the course of their pregnancy, clinical and behavioral information gathered, and pro-and antiinflammatory cytokines in monthly cervico-vaginal exudates and blood samples assayed. We are spatially locating the homes of these women in the Mexico City metropolitan area using global positioning system technology and estimating their exposure to five ambient pollutants using geo-statistical techniques. We will evaluate associations of these pollutant exposures with the cytokine measures in repeated measures design, as well as the association with preterm birth, and further evaluate effect modification by anti-oxidant vitamin intake and cytokine polymorphisms.

\subsection{Parallel toxicology study}

In a complementary, parallel toxicology study, we are obtaining monthly samples of particles from five regions of the MCMA near where the women live and evaluating their composition (metals, carbon and endotoxins). These regions are known to be impacted by different sources of pollution (natural -particularly windblown-dust, industrial, and traffic pollution). We are exposing a cell line to these particles and evaluating expression of the same cytokines as will be evaluated in the women. Differential responses according to region, likely related to different composition as previously suggested (Alfaro-Moreno et al., 2002), may be paralleled among the women, and guide future mechanistic research.

\subsection{Study location and sampling strategy}

Metropolitan Mexico City, altitude 2240 meters above sea level, is in a valley with mountains on three sides. Major pollution sources include vehicles, stationary combustion sources, and a dry lake basin that contributes windblown dust (O'Neill et al., 2004). The metropolitan population is estimated at 20 million (Brinkhoff, 2012). Pollution levels there are high relative to many U.S. and European cities, and $\mathrm{PM}_{10}$ and $\mathrm{O}_{3}$ regularly exceed national health-based standards.

We are recruiting women as they come seeking clinical care at health centers throughout the city. They are then referred to the Hospital Materno Infantil Inguaran (HMII), the biggest hospital within the Mexico City government public hospital network. The first visit involves a screening questionnaire and informed consent. Conservative power calculations based on logistic regression suggested that this sample size of 800 participants will enable detection of odds ratios for preterm birth from 1.43 to 1.70 per inter-quartile range increase in pollution over pregnancy, depending on the pollutant evaluated. Since we plan to employ survival analysis (O'Neill et al., 2003), these figures underestimate study power. We are interested in enrolling a broad geographic distribution of women across the metropolitan area, and approximately equal coverage of women by month across five major regions where the particle monitors are sited, so are working with other government health centers and hospitals to achieve this. 
Inclusion criteria require that the women 1) present at HMII with a pregnancy of less than 18 weeks gestation; 2) have a reliable recall of last menstruation and confirmatory ultrasound for gestational age; 3 ) agree to prenatal visits every 3 to 4 weeks throughout their current pregnancy; 4) give written consent for their inclusion in the study. Eligibility is determined at the first visit. Exclusion criteria include 1) living in a household outside the metropolitan area; 2) presence of any medical or obstetric complication in the current pregnancy; 3) self-reported smoker; 4) presence of multiple fetuses as determined by a physician's diagnosis. Women who develop pregnancy complications such as gestational diabetes and pre-eclampsia will be withdrawn from the study so these conditions can be treated; however, we keep track of their experiences. Study protocols and data collection instruments were reviewed and approved by the Institutional Review Boards of all participating institutions.

\subsection{Data collection and analytical methods}

Enrolled pregnant women are followed every 3 to 4 weeks during their pregnancy. At each visit, a questionnaire is administered to assess daily time activity patterns relevant to air pollution exposure (time spent at home and away from home); general health status, including infectious symptoms; and confirmation of basic social and demographic characteristics. Dietary intake is assessed by food frequency questionnaire and a multi-step 24 hour dietary recall for quantitative analysis. Nutritional status and weight gain are assessed at different times during the prenatal follow up. Occupation and smoking/ secondhand smoke exposure questions are also asked.

If symptoms of infection are present participants are treated with ad-hoc broad antibiotics. The women give blood, urine, saliva and cervico-vaginal exudate samples and are evaluated for presence of cervicovaginal infections and evidence of intrauterine infection.

Anthropometrics are obtained. Their nutritional state is evaluated using anthropometric and biochemical data, and diet counseling is given by trained dieticians. Participants provide a saliva sample for DNA analysis. At birth, the women provide a blood sample and umbilical cord blood is collected, and a saliva sample is taken from the infant. At the $22^{\text {nd }}$ week visit, a glucose tolerance test is administered to assess gestational diabetes, which is treated if present.

Glucose, lipids, creatinine, uric acid and cord blood acid-base assessment is run in a clinical chemistry laboratory according to routine assay schedules. The presence of cervico-vaginal and of urinary tract infections is evaluated at each visit. Samples of cervico-vaginal exudates and urine are evaluated using standard microbiological cultivation. If clinical infection is present, as determined by report and clinical exam, we supplement this method with a confirmatory molecular probe using polymerase chain reaction amplification followed by ribosomal DNA 16s identification for specific bacterial species using denatured gradient gel electrophoresis (DGGE) technique (Hillier, 2005). IL-2, IL-4, IL-10, IL-6, IL-8, IL-1 $\beta$ and $\mathrm{TNFa}$ will be measured in monthly cervico-vaginal exudate samples using the Millipore Magpix Multiplex system (Millipore Corporation, Billerica, Massachusetts). Ferritin is measured using a specific ELISA as an overall indicator of nutritional status. Vitamin C and $\mathrm{E}$ are determined in plasma and leukocytes using high pressure liquid chromatography (Bieri et al., 1979; Lee et al., 1982).

For the genetic analysis of cytokine polymorphisms, DNA will be extracted from saliva samples from mother and newborn using the Oragene system (Oragene 2007). The DNA fragments will be amplified with PCR and followed by a pattern analysis of the fragment size with restriction enzyme digestion (RFLP) or direct determination of the size of the amplified fragment. The genetic polymorphisms of interest are TNF- $\alpha$ (19), IL-1 $\beta$ and the antagonist of the IL-1 receptor (Pociot et al., 1992; Santtila et al., 1998; Wilson et al., 1992). 
Figure 1 is a summary chart showing data type and frequency of data collection.

\subsection{Air pollution exposure assessment}

The latitude and longitude of each woman's residential and working locations is recorded using a global positioning system (GPS) device, which will subsequently be used to determine each participant's proximity to emission sources. Spatial contrasts in exposure will allow for maximum use of residential information as well as reported time-activity patterns of subjects to further refine exposure estimates. We will use geostatistical kriging (Waller and Gotway, 2004), a method of exposure assessment that has been employed in air pollution studies (Leem et al., 2006; Liao et al., 2006), by assigning each mother to the exposure level that is predicted by a continuous surface of air pollution, weighted by her activities and proximity to monitors in the network. The purpose of kriging is to spatially predict potential air pollution exposure based on fixed and known locations of environmental data (i.e. Mexico City fixed-site air pollution monitors). Kriging is based on the spatial data characteristic of spatial autocorrelation: that observations closer together tend to be more alike than observations further apart. Spatial autocorrelation is quantified by a function called a semivariogram.

\subsection{Toxicology study}

This study is occurring over the same time frame as the enrollment of the epidemiologic cohort. We have selected five monitoring stations of the MCMA fixed-site monitoring network that represent a broad coverage of metropolitan area and zones with different pollution emission source mixes. Particles are being collected three times a week over 24 hours and pooled processed particles are added to cell cultures. Elemental analysis of particles will be accomplished by mass spectrometry with inductively coupled plasma (ICPMS). Particle samples ( $1 \mathrm{mg}$ ) will be used for carbon content determination using the evolved gas technique (Ellis et al., 1984) that has been previously applied to Mexico City measurements (Rosas Perez et al., 2007). Endotoxins are evaluated in $1 \mathrm{mg}$ particle samples by a kinetic chromogenic Limulus Amebocyte Lysate. The secretion of cytokines (IL-1 $\beta$, IL-1ra, IL-6, IL-8, IL-10, TNFa) by confluent 774A.1 cells stimulated with $40 \mu \mathrm{g} / \mathrm{cm}^{2}$ of particles (non-lethal concentrations) will be measured by the same Millipore Multiplex system.

\subsection{Integrating toxicology and epidemiology approaches}

Based on the sampling sites, we have divided the study area into five regions around each of the five fixed-site monitors using Thiessen polygons, where the point representing each monitor is a polygon centroid and the polygon boundary circumscribes the area closest to the given monitor. These polygons were used to 1) identify areas within which we are recruiting women for the epidemiologic study with an adequate distribution across the study area to ensure highest spatial contrast in pollution exposure, and 2) create indicator variables for each woman to evaluate concordance by region between epidemiologic and toxicologic study results. Figure 2 shows a schematic of how we are integrating these two approaches

\section{Preliminary Results}

To date, we have enrolled over 600 women in the study who live in the five regions of Mexico City and we are in the process of entering and quality checking the data from the extensive paper forms used by our study staff. Some pilot analyses from the epidemiologic study and preliminary construction of exposure metrics have been carried out. (CastilloCastrejon et al., 2011; Rivera et al., 2011; Smarr et al., 2011) 


\section{Discussion and Conclusions}

Preterm birth is a major public health problem of global consequence which may be influenced by exposure to air pollution, Therefore, understanding the mediating inflammatory and infectious pathways, using study designs such as the one described here, would provide further insights on mechanistic pathways linking pollution to adverse birth outcomes and potentially inform prevention efforts. Translation of research results in this field into in a clinical setting, in addition to the typical standards of care, might involve guidance relating to reduction in exposure to relevant pollutants, especially among those who may have a genetic susceptibility, or careful dietary supervision to ensure optimal resilience. Although interventions that target individual risk factors and behaviors are often emphasized in prenatal care, there is growing recognition that aspects of the environment, including air pollution, can have important consequences for fetal and infant health. Air pollution exposure is ubiquitous, so even small observed associations can have large overall impacts on public health. Ultimately, interdisciplinary collaborations can produce knowledge needed to inform preventive strategies as well as provide evidence supporting policies to target the most health-relevant emission sources, improve environmental quality and public health.

\section{Acknowledgments}

Support for this work provided by Grant R01 ES016932 from the U.S. National Institute for Environmental Health Sciences, National Institutes of Health.

\section{ABBREVIATIONS}

$\begin{array}{ll}\text { TSP } & \text { Total suspended particles } \\ \text { PM10 }_{10} & \text { Particulate matter less than } 10 \text { microns in aerodynamic diameter } \\ \text { PM}_{2.5} & \text { Particulate Matter less than } 2.5 \text { microns in aerodynamic diameter } \\ \text { CO } & \text { Carbon monoxide } \\ \mathbf{O}_{3} & \text { Ozone } \\ \text { SO }_{2} & \text { Sulfur dioxide } \\ \text { NO }_{2} & \text { Nitrogen dioxide } \\ \text { IOM } & \text { Institute of Medicine } \\ \text { NO } & \text { Oxides of nitrogen } \\ \text { TNF-a } & \text { Tumor necrosis factor -alpha } \\ \text { IL-12 } & \text { Interleukin 12 } \\ \text { IL-1 } \beta & \text { Interleukin 1-beta } \\ \text { IL-6 } & \text { Interleukin-6 } \\ \text { HMII } & \text { Hospital Materno Infantil Inguaran } \\ \text { DGGE } & \text { Denatured gradient gel electrophoresis } \\ \text { RFLP } & \text { Restriction fragment length polymorphism } \\ \text { PCR } & \text { Polymerase chain reaction } \\ \text { GPS } & \text { Global positioning system }\end{array}$




\section{References}

Alfaro-Moreno E, Martinez L, Garcia-Cuellar C, Bonner JC, Murray JC, Rosas I, et al. Biologic effects induced in vitro by $\mathrm{PM}_{10}$ from three different zones of Mexico City. Environ Health Perspect. 2002; 110:715-20. [PubMed: 12117649]

Behrman, RE.; Butler, AS., editors. Preterm Birth: Causes, Consequences, and Prevention. The National Academies Press; Washington, D.C.: 2007.

Bieri JG, Tolliver BS, Catiganai GL. Simultaneous determination of alpha tocopherol and retinol in plasma or red cells by high pressure liquid chromatography. Am J Clin Nutr. 1979; 32:2143-2149. [PubMed: 484533]

Brinkhoff T. The population of the major cities and agglomerations of countries in America. http:// www.citypopulation.de/America.html. Date.

Castillo-Castrejon, M.; Migoya, A.; Castañón, A.; Meraz-Cruz, N.; O’Neill, MS.; Vadillo Ortega, F. Presentation at International Society for Environmental Epidemiology. Barcelona, Spain: 2011. Evaluation of the frequency of consumption of foods containing genotoxic compounds in a cohort of Mexican pregnant women.

Ellis EC, Novakov T, Zeldin MD. Thermal characterization of organic aerosols. Sci Total Environ. 1984; 36:261-270.

Glinianaia SV, Rankin J, Bell R, Pless-Mulloli T, Howel D. Particulate air pollution and fetal health: a systematic review of the epidemiologic evidence. Epidemiology. 2004; 15:36-45. [PubMed: 14712145]

Hansen C, Neller A, Williams G, Simpson R. Maternal exposure to low levels of ambient air pollution and preterm birth in Brisbane, Australia. BJOG. 2006; 113:935-41. [PubMed: 16907939]

Hillier SL. The complexity of microbial diversity in bacterial vaginosis. N Engl J Med. 2005; 353:1886-7. [PubMed: 16267319]

Lee W, Hamernyik P, Hutchinson M, Raisys VA, Labbé RF. Ascorbic acid in lymphocytes: cell preparation and liquid-chromatographic assay. Clin Chem. 1982; 28:2165-2169. [PubMed: 7127749]

Leem JH, Kaplan BM, Shim YK, Pohl HR, Gotway CA, Bullard SM, et al. Exposures to air pollutants during pregnancy and preterm delivery. Environ Health Perspect. 2006; 114:905-10. [PubMed: 16759993]

Liao D, Peuquet DJ, Duan Y, Whitsel EA, Dou J, Smith RL, et al. GIS approaches for the estimation of residential-level ambient PM concentrations. Environ Health Perspect. 2006; 2006; 114(9): 1374-1380. [PubMed: 16966091]

Lin MC, Chiu HF, Yu HS, Tsai SS, Cheng BH, Wu TN, et al. Increased risk of preterm delivery in areas with air pollution from a petroleum refinery plant in Taiwan. J Toxicol Environ Health. 2001; 64:637-644.

Liu S, Krewski D, Shi Y, Chen Y, Burnett RT. Association between gaseous ambient air pollutants and adverse pregnancy outcomes in Vancouver, Canada. Environ Health Perspect. 2003; 111:1773-8. [PubMed: 14594630]

Maisonet M, Correa A, Misra D, Jaakkola JJK. A review of the literature on the effects of ambient air pollution on fetal growth. Environ Res. 2004; 95:106-115. [PubMed: 15068936]

Monn C, Becker S. Cytotoxicity and induction of proinflammatory cytokines from human monocytes exposed to fine (PM2.5) and coarse particles (PM10-2.5) in outdoor and indoor air. Toxicol Appl Pharmacol. 1999; 155:245-52. [PubMed: 10079210]

Nel AE, Diaz-Sanchez D, Li N. The role of particulate pollutants in pulmonary inflammation and asthma: evidence for the involvement of organic chemicals and oxidative stress. Curr Opin Pulm Med. 2001; 7:20-6. [PubMed: 11140402]

Ngoc NTN, Merialdi M, Abdel-Aleem H, Carroli G, Purwar M, Zavaleta N, et al. Causes of stillbirths and early neonatal deaths: data from 7993 pregnancies in six developing countries. Bull World Health Org. 2006; 84:699-705. [PubMed: 17128339]

O'Neill MS, Hertz-Picciotto I, Pastore LM, Weatherley B. Have studies of urinary tract infection and preterm delivery used the most appropriate methods? Pediatric Perinatal Epidemiol. 2003; 17:226233. 
O’Neill MS, Loomis D, Borja-Aburto VH. Ozone, area social conditions, and mortality in Mexico City. Environ Res. 2004; 94:234-242. [PubMed: 15016589]

Pociot F, Molvig J, Wogensen L, Worsaae H, Nerup J. A TaqI polymorphism in the human interleukin-1 beta (IL-1 beta) gene correlates with IL-1 beta secretion in vitro. Eur J Clin Invest. 1992; 22:396-402. [PubMed: 1353022]

Ritz B, Wilhelm M, Hoggatt KJ, Ghosh JK. Ambient air pollution and preterm birth in the environment and pregnancy outcomes study at the University of California, Los Angeles. Am J Epidemiol. 2007; 166:1045-52. [PubMed: 17675655]

Rivera, LO.; Sanchez, BN.; Zhang, K.; Zhang, Z.; Brines, SJ.; Brown, DG., et al. Comparing particulate matter and ozone exposure metrics for perinatal epidemiology in Mexico City, Mexico. Presentation at International Society for Environmental Epidemiology; Barcelona, Spain: 2011.

Rosas Perez I, Serrano J, Alfaro-Moreno E, Baumgardner D, Garcia-Cuellar C, Martin Del Campo JM, et al. Relations between $\mathrm{PM}_{10}$ composition and cell toxicity: a multivariate and graphical approach. Chemosphere. 2007; 67:1218-28. [PubMed: 17188738]

Salam MT, Millstein J, Li Y-F, Lurmann FW, Margolis HG, Gilliland FD. Birth outcomes and prenatal exposure to ozone, carbon monoxide, and particulate matter: results from the Children's Health Study. Environ Health Perspect. 2005; 113:1638-44. [PubMed: 16263524]

Santtila S, Savinainen K, Hurme M. Presence of the IL-1RA allele 2 (IL1RN*2) is associated with enhanced IL-1beta production in vitro. Scand J Immunol. 1998; 47:195-8. [PubMed: 9519856]

Sioutas C, Delfino RJ, Singh M. Exposure Assessment for Atmospheric Ultrafine Particles (UFPs) and Implications in Epidemiologic Research. Environ Health Perspect. 2005; 113:947-55. [PubMed: 16079062]

Slama R, Darrow L, Parker J, Woodruff TJ, Strickland M, Nieuwenhuijsen M, et al. Meeting report: atmospheric pollution and human reproduction. Environ Health Perspect. 2008; 116:791-798. [PubMed: 18560536]

Smarr, M.; O’Neill, MS.; Sanchez, BN.; Rivera, LO.; Beltran-Montoya, J.; Martinez, N., et al. Air pollution and repeated ultrasound measures of fetal growth in Mexico City. Presentation at International Society for Environmental Epidemiology; Barcelona, Spain: 2011.

Sram RJ, Binkova B, Dejmek J, Bobak M. Ambient air pollution and pregnancy outcomes: a review of the literature. Environ Health Perspect. 2005; 113:375-82. [PubMed: 15811825]

United Nations. [accessed: Oct. 17, 2012] UN Millenium Development Goals. 2000. http:// www.un.org/millenniumgoals/

Waller, LA.; Gotway, CA. Applied spatial statistics for public health data. John Wiley \& Sons, Inc.; Hoboken, New Jersey: 2004.

WHO. Occupational and Environmental Health Team. [accessed: Oct. 17, 2012] WHO Air quality guidelines for particulate matter, ozone, nitrogen dioxide and sulfur dioxide: Global update 2005: Summary of risk assessment. WHO/SDE/PHE/OEH/06.02, http://apps.who.int/iris/handle/ 10665/69477, 2006

Wilson AG, di Giovine FS, Blakemore AI, Duff GW. Single base polymorphism in the human tumour necrosis factor alpha (TNF alpha) gene detectable by NcoI restriction of PCR product. Hum Mol Genet. 1992; 1:353. [PubMed: 1363876]

Woodruff TJ, Parker JD, Darrow LA, Slama R, Bell ML, Choi H, Glinianaia S, Hoggatt KJ, Karr CJ, Lobdell DT, Wilhelm M. Methodological Issues in Studies of Air Pollution and Reproductive Health. Environ Res. 2009; 109:311-320. [PubMed: 19215915] 


\section{Inclusion criteria: must be yes to all; 800 women in final sample}

$<18$ weeks of pregnancy, $>18$ years old, non-smoker, single fetus, recalls last menstruation, ultrasound confirms gestational age, agrees to visit hospital every 4 weeks, lives in Mexico City, no pregnancy complications, no diabetes or pre-eclampsia

Informed consent: Samples, DNA analyses, global positioning system (GPS) permission

Monthly visits (at approximately 3, 4, 5, 6, 7 and 8 months of gestation) Questionnaire and location data

1) Demographics, previous pregnancies, behaviors, medical history $\left(1^{\text {st }}\right.$ visit-any updates in following visits)

2) Time-activity diary (for one weekday and one Sunday)-for estimated air pollution exposure

3) Food frequency questionnaire (alternate 24 hour recall with previous month's intake)

4) GPS coordinates of home residence, work location (if she works outside of home)-obtained once unless she changes residence or place of work

\section{Clinical data}

1) Anthropometric and clinical measures; ultrasound of baby; glucose tolerance test (22 weeks)

2) Status of actual pregnancy and clinical evaluation

3) Samples obtained from women: blood, urine, and cervico-vaginal exudates; saliva (one visit only)

Birth: Infant characteristics, gestational age and baby's saliva (for genotyping) are obtained Mother's blood and a sample of umbilical cord blood obtained

Figure 1.

Air pollution and preterm birth in Mexico City: Summary of data collection 


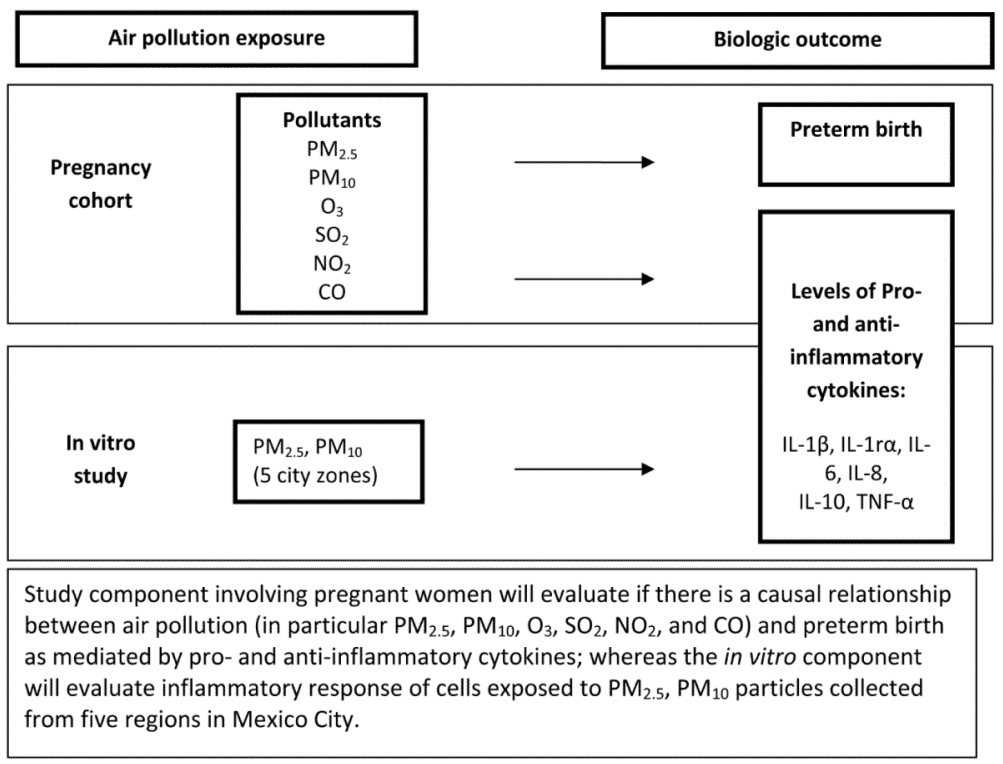

Figure 2.

Overall schematic of study design integrating toxicology and biologic outcome 